\title{
ERRATUM
}

Beate Ulbrich · Ralf Stahlmann

\section{Developmental toxicity of polychlorinated biphenyls (PCBs): a systematic review of experimental data}

\section{Arch Toxicol (2004) 78:252-268}

The reference to the electronic supplementary material accompanying the article was omitted. In addition, Figs.
$1,2,3$, and 4 were erroneously printed in black-andwhite rather than color. The color figures are reproduced here.

Electronic Supplementary Material Supplementary material is available in the online version of this article at http://dx.doi.org/ 10.1007/s00204-004-0583-y.

The online version of the original article can be found at http:// dx.doi.org/10.1007/s00204-004-0519-y

B. Ulbrich

Federal Institute for Risk Evaluation,

Thielallee 88-92, 14195 Berlin, Germany

R. Stahlmann $(\bowtie)$

Department of Toxicology,

Institute of Clinical Pharmacology and Toxicology,

Campus Benjamin Franklin,

CHARITÉ Universitätsmedizin Berlin,

Garystrasse 5, 14195 Berlin, Germany

E-mail: ralf.stahlmann@charite.de

Tel.: + 49-30-84451770

Fax: +49-30-84451763 


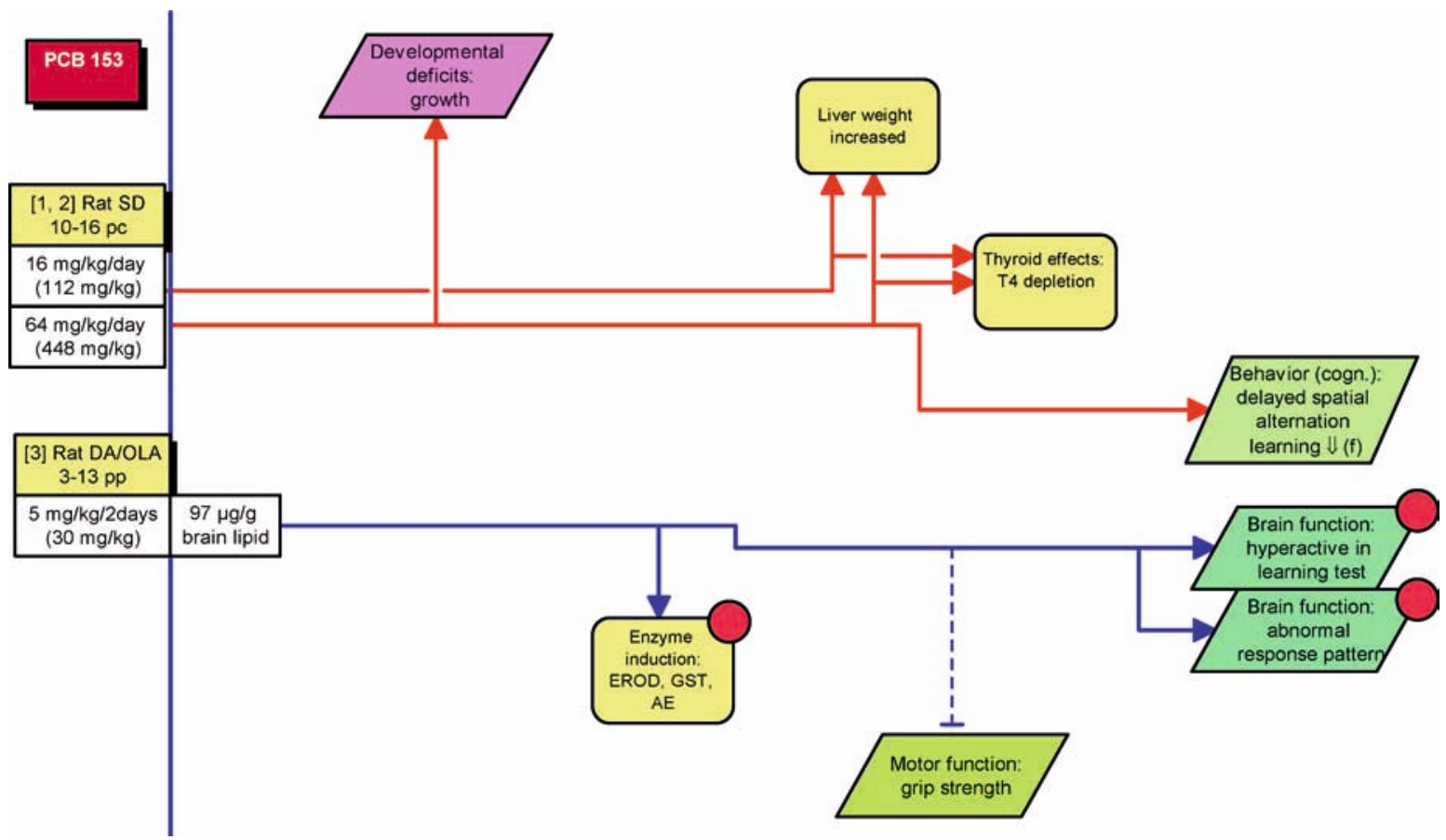

Fig. 1 PCB 153. Three studies in two different rat strains were evaluated, two with prenatal and one with postnatal exposure of the dam. Reference numbers in square brackets, as well as strain, exposure period, daily dose and cumulative dose (in brackets) are listed on the left side of the figure. Brain PCB levels were measured only in the postnatal exposure study. Colored arrows indicate the tested parameters that were affected $(\mathrm{m}=$ male, $\mathrm{f}=$ female $)$. The line ending in a bar (no arrow head) indicates that grip strength was unaffected by postnatal exposure through the milk. The most sensitive parameters in this set of studies (affected at the lowest dose tested) are marked with red dots. Publications considered are: [1] Ness et al. (1993); [2] Schantz et al. (1995); [3] Holene et al. (1998)

Fig. 2 PCB 77. Fourteen studies in three different strains of rats $(\mathrm{SD}=$ Sprague-Dawley, $\mathrm{LE}=$ Long-Evans, Wistar Rats $)$ were evaluated, all of them with exposure through the mother animal. Reference numbers in square brackets, as well as strain, exposure period, daily dose and cumulative dose (in brackets) are listed on the left side of the figure. Colored arrows indicate the tested parameters that were affected $(\mathrm{m}=$ male, $\mathrm{f}=$ female $)$. The most sensitive parameters in this set of studies (affected at the lowest dose tested) are marked with red dots. Exposure to $3 \mathrm{mg} / \mathrm{kg} / \mathrm{day}$ during the fetal period reduced pup viability (dose field marked in red). All other dose regimens were compatible with postnatal survival of the offspring. Two studies provided PCB brain levels and one study found hydroxylated metabolites to be the main PCB compounds in the fetuses. Growth reduction, delayed eye opening, alterations in anogenital distance in males (decrease) and females (increase), increased sperm counts, decreased sexual receptivity in females and an increase in brain dopamine/dopamine turnover were the most sensitive parameters in different studies. Publications considered are: [1] Faqi et al. (1998); [2] Morse et al. (1995); [3] Altmann et al. (1995); [4] Roth-Härer et al. (2001); [5] Weinand-Härer et al. (1997); [6] Hany et al. (1999a); [7] Altmann et al. (1998); [8] Wang et al. (2002); [9] Seegal et al. (1997); [10] Amin et al. (2000); [11] Schantz et al. (1996); [12] Schantz et al. (1997a); [13] Seo et al. (1995); [14] Simmons et al. (1984) 


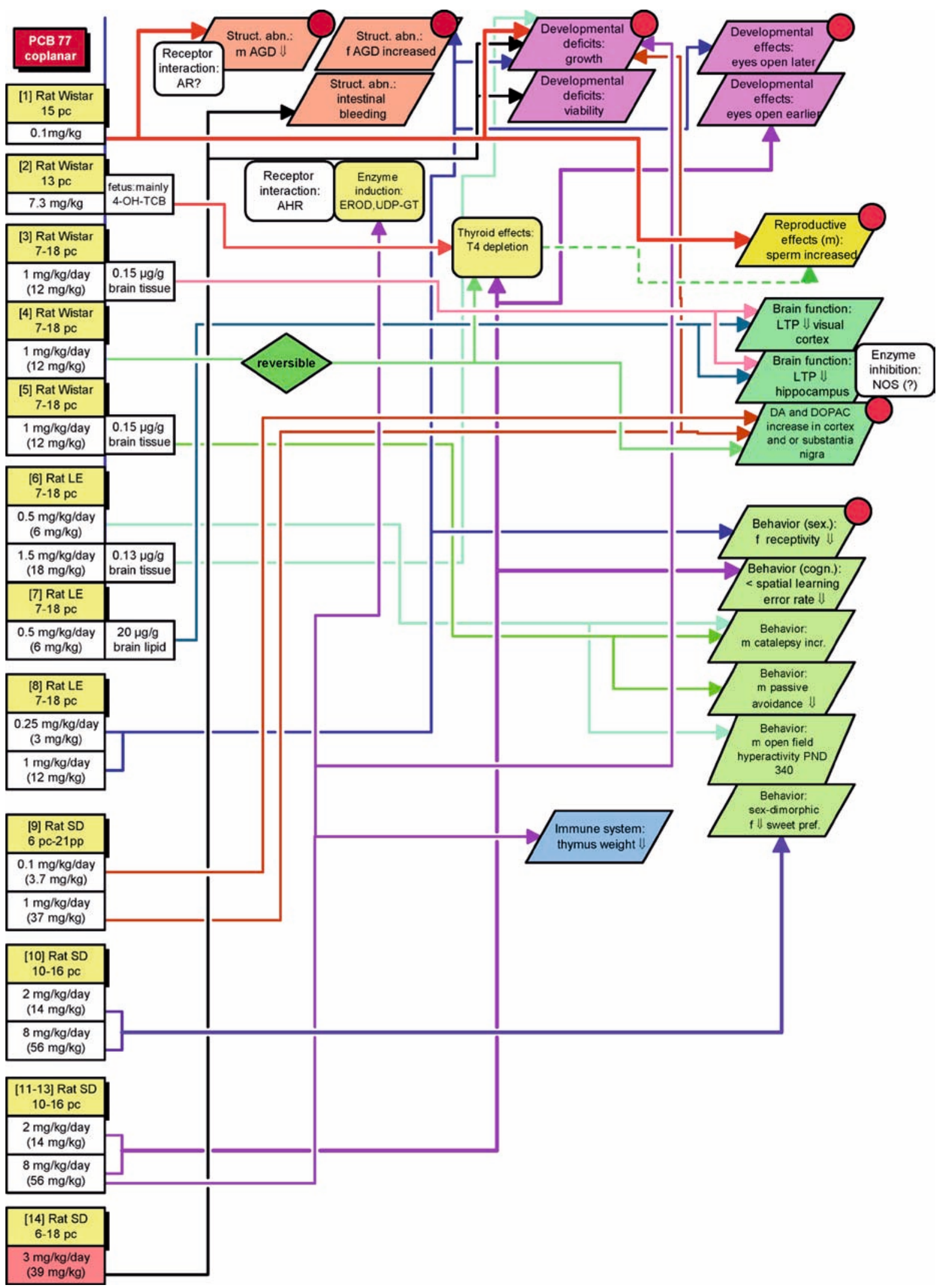




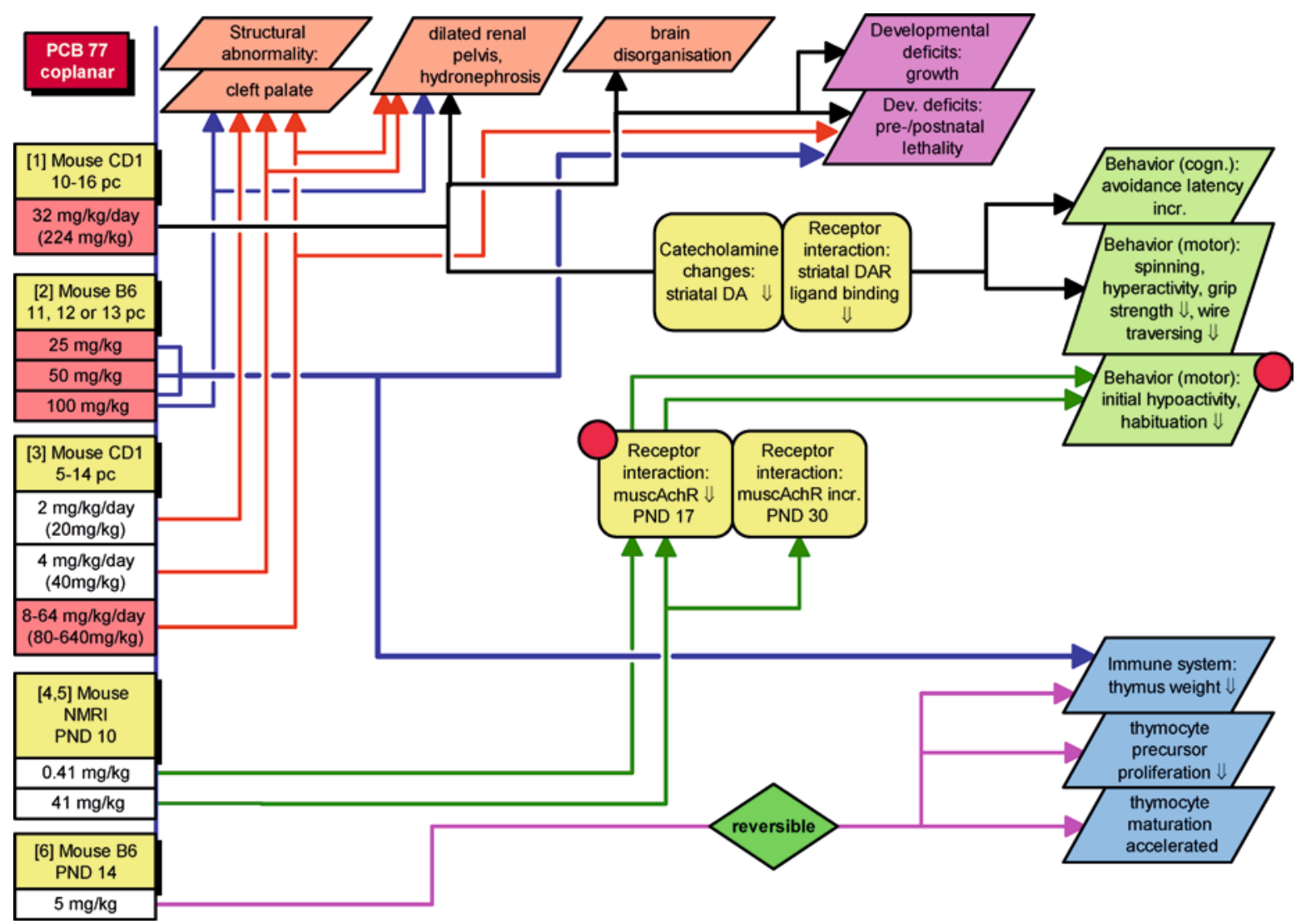

Fig. 3 PCB 77. Six studies in three different strains of mice $(\mathrm{B} 6=\mathrm{C} 57 \mathrm{BL} / 6)$ were evaluated, two of them with direct postnatal exposure of the offspring. Reference numbers in square brackets, as well as strain, exposure period, daily dose and cumulative dose (in brackets) are listed on the left side of the figure. Colored arrows indicate the tested parameters that were affected $(\mathrm{m}=$ male, $\mathrm{f}=$ female). The most sensitive parameters in this set of studies (affected at the lowest dose tested) are marked with red dots. Dose levels of $8 \mathrm{mg} / \mathrm{kg}$ or higher were overtly toxic for the conceptus of the offspring (dose field marked in red) and therefore cannot be considered relevant for current human exposure. This includes the only study where behavioral parameters were tested after exposure in utero. No PCB tissue levels were available for any of the studies. NMRI mouse pups treated with a single low dose postnatally displayed a decrease of muscarinic receptor binding in the hippocampus in the preweaning period and an altered motor activity pattern when tested in the open field as adults. This was characterized by decreased initial exploratory activity and a lack of habituation over time. Publications considered are: [1] Agrawal et al. (1981); [2] d'Argy et al. (1987); [3] Marks et al. (1989); [4] Eriksson (1988); [5] Eriksson (1991); [6] Esser et al. (1994) 
Fig. 4 Summary of behavioral effects of PCBs in rats and mice (for details see supplementary electronic material). Changes in behavioral parameters, brain biochemistry or electrophysiology have been observed for most of the PCB congeners and mixtures evaluated in this review. However, not all of the effects were detrimental. Spatial memory was found to be improved in rats that were exposed to the coplanar congeners 77 and 126 during development. The learning impairment observed with other PCBs appears to be unrelated to the decrease in circulating thyroid hormone because it also appeared when plasma T4 was unaffected (PCB 28). Overall, the data available for individual compounds and mixtures are insufficient to derive patterns of action on the brain and the resulting behavioral changes. For references and more details see Table 2

\begin{tabular}{|c|c|c|c|c|c|c|c|c|}
\hline \multicolumn{2}{|l|}{ Behavioral effects overview } & \multicolumn{3}{|l|}{ Rat } & \multirow[b]{2}{*}{$s \times$} & \multirow[b]{2}{*}{ NT } & \multirow[b]{2}{*}{ T4 } & \multirow[b]{2}{*}{ EP } \\
\hline & & LM & MA & GD & & & & \\
\hline 2,2',5-trichlorobiphenyl & РCB 18 & & & & & & & \\
\hline 2,4,4'-trichlorobiphenyl & PCB 28 & & & & & & & \\
\hline 2,2',4,4'-tetrachlorobiphenyl & PCB 47 & & & & & & & \\
\hline 3,3',4,4'-tetrachlorobiphenyl & PCB 77 & & & & & & & \\
\hline 2,2',3,5',6-pentachlorobiphenyl & РCB 95 & & & & & & & \\
\hline 2,2',4,5,5'-pentachlorobiphenyl & PCB 101 & & & & & & & \\
\hline $2,3^{\prime}, 4,4^{\prime}, 5$-pentachlorobiphenyl & PCB 118 & & & & & & & \\
\hline 3,3',4,4',5-pentachlorobiphenyl & PCB 126 & & & & & & & \\
\hline 2,2',4,4',5,5'-hexachlorobiphenyl & PCB 153 & & & & & & & \\
\hline 3,3',4,4',5,5'-hexachlorobiphenyl & PCB 169 & & & & & & & \\
\hline Aroclor 1254 & Composition & & & & & & & \\
\hline $\mathrm{PCB}$ reconstituted mixture & Composition & & & & & & & \\
\hline Clophen A30 & Composition & & & & & & & \\
\hline
\end{tabular}

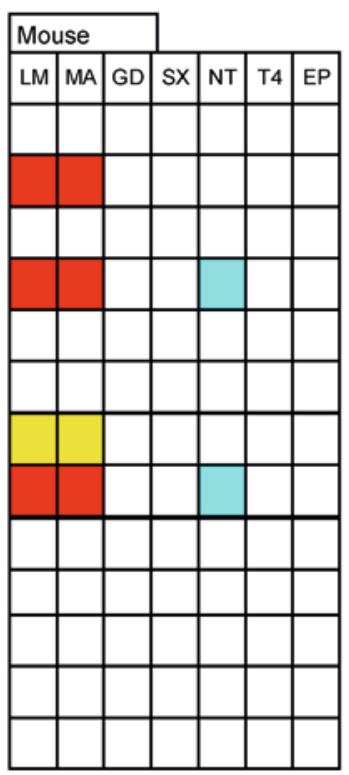

$$
\begin{array}{|ll}
\hline \text { LM } & \text { Learning/Memory } \\
\text { MA } & \text { Motoractivity } \\
\text { GD } & \text { Gender dimorphic } \\
\text { SX } & \text { Sexual behavior } \\
\text { NT } & \text { Neurotransmitters/Receptors } \\
\text { T4 } & \text { Thyroxine plasma level } \\
\text { EP } & \text { Long-term potentiation }
\end{array}
$$

